\title{
Spirometric Values of petrol pump workers of Lahore: A cross sectional study
}

\author{
WAQAS ASLAM ${ }^{1}$, M. ZUBAIR ASHRAF ${ }^{2}$, M. SAQIB SAEED ${ }^{3}$, FARIHA SALMAN ${ }^{4}$ \\ ${ }^{1}$ Assistant Prof. Pulmonology M Islam Medical \& Dental College Gujranwala, Pakistan. \\ ${ }^{2} S R, U K$ \\ ${ }^{3}$ Chairman Department of TB and Chest diseases Mayo Hospital Lahore, Pakistan. \\ ${ }^{4}$ Assistant Professor, Dept. of Community Medicine, King Edward Medical University Lahore, Pakistan. \\ Correspondence to Dr. Waqas Aslam, Email: wakas.aslam@gmail.com
}

\begin{abstract}
Background: Petrol pump workers are exposed to air pollution and fumes of petrol and diesel that may lead to poor lung function followed by chronic diseases, where the city is highly polluted.

Aim: To determine lung functioning capacity by spirometry among petrol pump workers

Methods: A cross sectional study was designed and conducted in the pulmonology department of Mayo, hospital Lahore. Two seventy five (275) subjects were enrolled in the study after fulfilling the inclusion/exclusion criteria and giving informed consent by consecutive sampling. Information like name, age, weight, height, duration of working was recorded. Spirometry was performed to calculate FEV1, FVC and FEV1/FVC ratio. Data was entered and analyzed by statistical software SPSS version 23. Mean and standard deviation of age, height, weight, and work duration, Spirometric values for lung functions (FEV1, FVC and FEV1/FVC Ratio) were calculated. Data was divided into groups by age and work duration and spirometric values for lung functions were compared in these groups. T test \& Pearson correlation was used for analysis and $p$ value less than 0.05 was considered significant.

Results: Participant age was 28.75 \pm 6.89 .FEV1 was2.35 \pm 0.44 , FVC $3.18 \pm 0.66$ and FVC 74.91+9.40. FEV1 \& FEV1/FVC ratio were significantly different $(p<0.05)$ in age groups $(<30, \geq 30)$ \& work duration groups $(<8, \geq 8 y e r a s)$. Negative Correlation was found between work duration \& lung functions (FEV1, FEV1/FVC ratio).

Conclusion: Spirometric values were lower in petrol pump workers. Age and working duration further affects lung function of petrol pump workers.

Keywords: FVC, FEV1, Spirometer, Petrol Pump Workers, Pulmonology
\end{abstract}

\section{INTRODUCTION}

Petrol pump workers (PPWs) are exposed to fumes of petrol and diesel through their job. Petrol and diesel fumes are considered to be injurious to lungs and general health of the subjects. Increase in the number of vehicles adds on to the problem. With Urbanization and raising number of vehicles, need for the petrol pumps and attendants working there are also rising ${ }^{1,2}$. In countries like Pakistan, petrol pump workers add fuel to the vehicles coming to petrol pump for filling. They are exposed to vehicle pollution, fumes of petrol or diesel while detaching from dispenser and vehicle 3,4 . Lahore is one of the most polluted cities of Pakistan ${ }^{5}$. This pollution adds o to the issue.

Both petrol and diesel undergo combustion in automobile engines and give rise to combustion-derived nano particles. These particles are highly respirable and have a large surface area which can carry a larger fraction of toxic hydrocarbons and metals on their surface. Up to 8 hours of benzene exposure concentrations usually average $<1 \mathrm{ppm}$, but the exposures can reach up to 2-3ppm. Common aromatic compounds in the petroleum products are benzene, ethylbenzene, xylene and toluene. These are volatile. They easily disperse in air and become respirable 6 . A spirometer is used for measuring the volume of air inspired and expired by the lungs. Some recent studies reported compromised lung functions among petrol pump workers. Different studies used parameters like FEV1 (forced expiratory volume in 1 second), FVC (forced

Received on 13-02-2021

Accepted on 23-06-2021 vital capacity), FEV1/FVE ratio, PEFR (peak expiratory flow rate) etc. to establish lung functions ${ }^{7-10}$.

Petrol pump workers are exposed to air pollution and fumes of petrol and diesel that may lead to poor lung function followed by chronic diseases. Current study is an effort to determine current level of lung function among petrol pump workers of a polluted city, Lahore. Most of the PPWs are poor and do not afford medical checkups and do not have enough information about preventive health. Routinely preventive measures are not practiced at petrol pumps. Results of this study will help poor petrol pump workers community by highlighting this issue and policy makers to make policies for prevention, control and compensation.

The objective of the study was to determine lung functioning capacity by spirometry among petrol pump workers

\section{METHODS}

Epidemiological Design of the study was cross sectional and this was conducted in the Pulmonology Department of Mayo, Hospital Lahore after approval from Ethical Committee. Two hundred seventy five (275) subjects were enrolled in the study after fulfilling the inclusion/exclusion criteria and giving informed consent by consecutive sampling (non-probability sampling). Sample size was calculated at $95 \%$ confidence interval and $1 \%$ margin of error by "World Health Organization software for sample size calculation" using reference value of FEV1/ FVC ratio of $88.13 \pm 8.44 \%{ }^{4}$. Males Petrol Pump workers of age $18-40$ years working 08 hours a day for more than 2 years were 
included in the study whereas smokers, tobacco chewers, morbidly obese with $\mathrm{BMI}>35 \mathrm{~kg} / \mathrm{m} 2$, patients of chronic respiratory illness like asthma, chronic obstructive pulmonary disease and who had abdominal or chest surgery were excluded from the study on the basis of history and examination.

Subjects fulfilling criteria were enrolled in study after obtaining informed consent and were called at pulmonology department for spirometry. Their information like name, age, weight, height, duration of working was recorded. Procedure of spirometry was explained to the subjects. Spirometry was performed to calculate FEV1, FVC and FEV1/FVC ratio by field expert as per standard procedure. Volume of air expelled in 1st second after a maximum inspiration is known as FEV1 whereas maximum volume of exhaled is FVC and their ratio is FEV1/FVC ratio (normal range: $70-85 \%$ ) Values obtained were recorded on a proforma.

After collection, data was entered and analyzed by SPSS version 23. For descriptive statistics minimum \& maximum values with mean and standard deviations of Age, Height, Weight, Work Duration, Spirometric values for lung functions (FEV1, FVC and FEV1/FVC Ratio) were calculated. Data was divided into groups firstly in age groups of below 30 years and 30 and above, secondly by duration of working in years, below 8 years and 8 and above years. Then spirometric values for lung functions (FEV1, FVC and FEV1/FVC Ratio) were compared in these groups. T test was applied for comparison and cut off level was $p<0.05$ to be labeled as significant. Pearson Correlation was applied to see correlation between work duration and lung functions (FEV1, FVC and FEV1/FVC Ratio) with the same cut off value as set for T test.

\section{RESULTS}

Two seventy five (275) subjects were enrolled in the study after fulfilling the inclusion/exclusion criteria and giving informed consent. Participant age was 28.75 \pm 6.89 .FEV1 was2.35 \pm 0.44 , FVC $3.18 \pm 0.66$ and FVC 74.91 \pm 9.40 . Descriptive statistics of Age, Height, Weight, Work Duration, Spirometric values for lung functions (FEV1, FVC and FEV1/FVC Ratio) are given in Table 1. Data was stratified by age groups (below and 30 or above and duration of work (below and 8or more). Spirometric values for lung functions (FEV1, FVC and FEV1/FVC Ratio) were compared in these groups. FEV1 \& FEV1/FVC ratio were significantly different $(p<0.05)$ in these groups whereas FVC was not significantly different and are shown in Table 2. Negative correlation was found between work duration and FEV1 \& FEV1/FVC Ratio as shown in Table 3.

Table 1: Descriptive Statistics of Study Variables
\begin{tabular}{|l|l|l|l|l|}
\hline Variable & Min. & Max. & Mean & St. Deviation \\
\hline Age (years) & 18 & 40 & 28.75 & 6.89 \\
\hline Height( meters) & 1.63 & 1.86 & 1.69 & 0.05 \\
\hline Weight(Kg) & 55 & 90 & 73.51 & 7.21 \\
\hline Work duration (years) & 3 & 12 & 6.43 & 2.96 \\
\hline FEV1 (L) & 1.3 & 3 & 2.35 & 0.44 \\
\hline FVC(L) & 1.8 & 5 & 3.18 & 0.66 \\
\hline FEV1/FVC Ratio & 56.52 & 96.67 & 74.91 & 9.40 \\
\hline
\end{tabular}

Table 2: Comparison of Spirometric Values in Different Age Groups and Different Work Duration

\begin{tabular}{|l|c|c|c|c|c|}
\hline \multirow{2}{*}{ Variables } & \multicolumn{2}{|c|}{ Age Below 30 } & \multicolumn{2}{c|}{ Age Above or equal to 30 } & T test ( P value) \\
\cline { 2 - 6 } & Frequency & Mean \pm SD & Frequency & Mean \pm SD & \\
\hline FEV1 $(\mathrm{L})$ & 150 & $2.43 \pm 0.38$ & 125 & $2.26 \pm 0.49$ & $3.11(0.003){ }^{*}$ \\
\hline FVC $(\mathrm{L})$ & 150 & $3.17 \pm 0.57$ & 125 & $3.18 \pm 0.76$ & $0.097(0.92)$ \\
\hline FEV1/FVC ratio & 150 & $77.40 \pm 9.34$ & 125 & $71.93 \pm 8.60$ & $5.04(0.000)^{*}$ \\
\hline & Work Duration Less than 8 years & Work Duration 8 or more years & \\
\hline FEV1(L) & 201 & $2.43 \pm 0.38$ & 74 & $2.14 \pm 0.51$ & $4.47(0.000)^{*}$ \\
\hline FVC $(\mathrm{L})$ & 201 & $3.20 \pm 0.54$ & 74 & $3.11 \pm 0.91$ & $0.82(0.42)$ \\
\hline FEV1/FVC ratio & 201 & $76.66 \pm 8.98$ & 74 & $70.16 \pm 8.91$ & $5.33(0.00){ }^{*}$ \\
\hline
\end{tabular}

Table 3: Correlation between work duration and FEV1, FVC \& FEV1/FVC Ratio

\begin{tabular}{|l|l|l|l|}
\hline & FEV1(L) & FVC(L) & FEV1/FVC ratio \\
\hline Pearson correlation & -.233 & -.044 & -.469 \\
\hline P value & $0.000^{*}$ & 0.468 & $0.000^{*}$ \\
\hline
\end{tabular}

Significant ${ }^{*}$

\section{DISCUSSION}

Due to environmental pollution and constant exposure of petrol/diesel at workplace without preventive measures, lungs functioning capacity of PPWs is affected. Mean age of the PPWs was $28.75 \pm 6.89$ in this study. In a study conducted in Karachi mean age of the PPWs was $28.63 \pm 1.5^{3}$.

FEV1 among petrol pump was $2.35 \pm 0.44$, FVC was $74.91 \pm 9.40$ and $F E V 1 / F V C$ ratio was74.91 $\$ 9.40$. A recent study conducted in Nigeria compared to healthy controls and found significant reduction in FEV1, FVC and PEPR.
Respiratory symptoms including cough and pain in chest were frequently observed. The study concluded that breathing at petrol pump is the source of inhaling fumes that seriously affects respiratory organs ${ }^{8}$.

Spirometric parameters were low in age group $\geq 30$ when compared to $<30$ years of age group. Studies supported our findings.FEV1 and FEV1/FVC ratio was significantly different whereas FVC was low but not significantly different in present study. This factor was not directly studied by majority of the studies considering it confounder. But study found relation of exposure with increasing age significant ${ }^{1}$.

A study was conducted to assess the ventilatory functions of the same field workers. They reported that workers were not taking appropriate preventive measures. They were not receiving routine medical examination and follow ups. They even did not have enough knowledge about the consequences of their job on health. Obstructive, mixed and restrictive functional disorders were observed 
with obstructive being most prevalent. Among smokers' obstructive disorders was more frequent and after 10 years of exposure restrictive pattern was more frequent ${ }^{11}$.

Another study tested lung functions by PEFR (peak expiratory flow rate) and found marked reduction in its value in PPWs. They found mild effect on exercising capacity as well as quality of life ${ }^{12}$.

In a study conducted in India lung functions were impaired. There was reduction in the parameters like FEV1, FVC, TV, and PEFR. When compared to control group all were significant except FEV1/FVC ratio. Both obstructive and restrictive patterns were found. ${ }^{13} \mathrm{An}$-other study conducted at Al Medina Al Munawara city found restrictive pattern predominantly. Obstructive pattern was less predominant ${ }^{14}$.

A study conducted in Bhopal could not find significant effects on lung functions of both PPWs and rickshaw drivers after 9 years of work duration. Researchers suggested that may be due to low environmental pollution in that particular city ${ }^{15}$. Studies conducted in Karachi, Pakistan found significant deleterious effect of pollutant fumes on PPWs lungs functioning ${ }^{2,3,16}$ Similar findings were presented by other studies in neighbor country $1,7,17$.

Spirometric parameters were low in group with $\geq 8$ years working duration when compared to $<8$ group.FEV1 and FEV1/FVC ratio were significantly different whereas FVC was low but not significantly different in present study. In a study conducted at Chennai respiratory functions were found to be declined when compared with control group and with increase duration of exposure the impairment was reported more representing with more reduce functions ${ }^{18}$. A study conducted at Ahmadabad also concluded that with dysfunction progresses with prolong exposure ${ }^{1}$.

Negative correlation was found between work duration and FEV1 \& FEV1/FVC Ratio in our study and similar to reported previously 8,19 .

Limitations of this study are cross sectional study design, single city, convenient sampling.

Recommendations are to conduct more analytical and experimental studies and make policies for prevention, control and compensation. Studies must be planned for preventive knowledge and practices. Pre placement and regular medical checkup for pulmonary health must be planned.

\section{CONCLUSION}

Spirometric values were lower in petrol pump workers. Age and working duration further affects lung function of petrol pump workers.

Contribution of authors: WA: Basic idea, preparation and revision of the manuscript, literature review, data collection \& final approval, MZA: Conception of the basic idea, literature search, preparation and revision, data collection, data entry and final approval, MSS: Helped in conception of the basic idea, literature search, preparation and revision and final approval, FS: Helped in conception of the basic idea, literature search, preparation and revision, data analysis and final approval.

Conflict of Interest: None

\section{Funding Source: None REFERENCES}

1. Solanki RB, Bhise AR, Dangi BM. A study on spirometry in petrol pump workers of Ahmedabad, India. Lung India 2015;32:347-52.

2. Zafar M. Correlation of respiratory symptoms and spirometric lung pattern among petrol pump workers Karachi, Pakistan: Crosssectional survey. Int J Health Syst Disaster Manage 2016;4:3640. 3 .

3. Rutaba A, Amsa Z, Asmara G, Aiman N, Quratulain A, Prof. Fauzia I. Lung function abnormalities among fuel filling workers in Karachi, Pakistan Pinnacle Envir Earth Sci. 2014;1(1):183-7.

4. Begum S, Rathna M. Pulmonary function test in petrol filling workers in Mysore city. Pak J Phys. 2012;8(1):12-4.

5. Ahmad M, Cheng S, Yu Q, Qin W, Zhang Y, Chen J. Chemical and source characterization of PM2. 5 in summertime in severely polluted Lahore, Pakistan. Atmospheric Research. $2020 \mathrm{Apr}$ 1;234:104715.

6. Kuranchie FA, Angnunavuri PN, Attiogbe F, Nerquaye-Tetteh EN. Occupational exposure of benzene, toluene, ethylbenzene and xylene (BTEX) to pump attendants in Ghana: Implications for policy guidance. Cogent Environmental Science. 2019 Jan 1;5(1):1603418

7. Sumathi $P$, Neelambikai N. Evaluation of pulmonary functions in petrol pump workers. Indian J Clin Anat Physiol 2016;3:189-94.

8. Dissi GM. Assessment of cardiopulmonary function and respiratory symptoms among petrol pump attendants in Kano metropolis. Dutse J Pure Appl Sci 2018;4:374-82.

9. Zolfaghari A, Zarei A, Mostaghaci M, Mihanpour $H$. The effect of respiratory exposure to benzene, toluene, xylene and ethyl benzene on the spirometric indices among the petroleum products loading workers. Occupational Medicine Quarterly Journal.;11(4):84-90.

10. Okemuo AJ, Ominyi LA, Ojukwu CP, Uchenwoke CI, Chukwu CS, Ezugwu UA. Assessment of respiratory symptoms and cardiopulmonary indices among petrol pump attendants in Enugu Metropolis. International Journal of Medicine and Health Development. 2020 Jul 1;25(2):106-.

11. Mbengue A, Coly MS, Faye SH, Sow AK, Diaw M, Sarr FB. Impact of Fuel Exposure on Ventilatory Function among Petrol Pump Attendants in Thies, Senegal. International Journal of Physiology. 2020 Mar 1;8(1):130-5.

12. Gaikwad PA, Gawand AA, Naik R. Assessment of Lung Function, Exercise Capacity and Quality of Life in Petrol Pump Workers.2020

13. KODIDALA DS. Pulmonary function tests in petrol pump workers exposed for three years to petrol/diesel fumes in Mathura District Uttar Pradesh. International Journal of Current Research in Physiology and Pharmacology. 2020 Feb 23:10-3.

14. Awadallah MF, Abdelgawad TT, Shendy MA, Al-Shenqiti AM, Abumossalam AM. Pulmonary Misfortune Ensuing to Petroleum Related Employments. Open Journal of Respiratory Diseases. 2020 Apr 3;10(2):21-31.

15. Deora K, Hulke SM, Bhargava DC. Comparison of Pulmonary Function Test in Petrol Pump Worker and Auto-rickshaw Driver. Advanced biomedical research. 2019;8.

16. Alam ${ }^{1} \mathrm{R}$, Zafar A, Ghafoor A, Naseem ${ }^{4} A, A^{5}{ }^{5}$ Q, Imtiaz ${ }^{6}$ F. Lung function abnormalities among fuel filling workers in Karachi, Pakistan. Cough. 2014;21(78.6):0-28.

17. Chakraborty D, Aggarwal M, Paul D. A comparative evaluation of respiratory indices in petrol station workers of Agartala. Int J Basic Appl Physiol. 2016;5(1):173.

18. Santhalingam ${ }^{1}$ B, Mahajan MV. Lung Function Abnormalities in Petrol Pump Workers in Suburban Areas of Chennai. Annals of International Medical and Dental Research. 2017;3(5):1.

19. Moghadam SR, Afshari M, Moosazadeh M, Khanjani N, Ganjali A. The effect of occupational exposure to petrol on pulmonary function parameters: a review and meta-analysis. Reviews on Environmental Health. 2019 Dec 18;34(4):377-90. 